Technological University Dublin

DÜBLIN

ARROW@TU Dublin

\title{
Effects of Single Mutations on the Stability of Horseradish Peroxidase to Hydrogen Peroxide.
}

\author{
Barry Ryan \\ Technological University Dublin, barry.ryan@tudublin.ie \\ Ciarán Fagan \\ Dublin City University, ciaran.fagan@dcu.ie
}

Follow this and additional works at: https://arrow.tudublin.ie/schfsehart

Part of the Life Sciences Commons

\section{Recommended Citation \\ Ryan, B.J. and O'Fágáin, C. (2007). Effects of single mutations on the stability of horseradish peroxidase to hydrogen peroxide. Biochimie, 89, (8), 1029-1032. http://dx.doi.org/10.1016/j.biochi.2007.03.013}

This Article is brought to you for free and open access by the School of Food Science and Environmental Health at ARROW@TU Dublin. It has been accepted for inclusion in Articles by an authorized administrator of ARROW@TU Dublin. For more information, please contact arrow.admin@tudublin.ie, aisling.coyne@tudublin.ie, gerard.connolly@tudublin.ie.

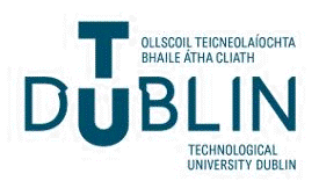




\title{
Effects of single mutations on the stability of Horseradish Peroxidase to hydrogen peroxide.
}

\author{
Barry J. Ryan and Ciarán Ó’Fágáin*. \\ School of Biotechnology and National Centre for Sensors Research, Dublin City \\ University, Dublin 9, Ireland. \\ * corresponding author: Ciarán Ó'Fágáin (Ciaran.Fagan@dcu.ie). \\ Phone: +353-1-700 5288 \\ Fax: $\quad+353-1-7005412$
}

Short Title: Increased peroxide stability of Horseradish Peroxidase mutants.

Key Words: Recombinant, Horseradish Peroxidase, Mutagenesis, Peroxide, Stabilisation.

\begin{abstract}
Abbreviations: $\delta$-ALA: Delta Aminolevulinic AcidHRP, horseradish peroxidase isoenzyme $\mathrm{C}$; $\mathrm{PDB}$, protein data bank; rHRP, recombinant horseradish peroxidase isoenzyme C; TMB, 3,3',5'5-Tetramethyl Benzidine.
\end{abstract}




\begin{abstract}
:
Horseradish Peroxidase (HRP) is a commonly used enzyme in many biotechnological fields. Improvement of HRP stability would further increase its potential application range. In the present study, thirteen single- and three double- mutants of solvent exposed, proximal lysine and glutamic acid residues were analysed for enhanced $\mathrm{H}_{2} \mathrm{O}_{2}$ stability. Additionally, five single- and one pentuple-consensus mutants were investigated. Most mutants displayed little or no alteration in $\mathrm{H}_{2} \mathrm{O}_{2}$ stability; however, three $(\mathrm{K} 232 \mathrm{~N}, \mathrm{~K} 241 \mathrm{~F}$ and $\mathrm{T} 110 \mathrm{~V})$ exhibit significantly increased $\mathrm{H}_{2} \mathrm{O}_{2}$ tolerances of 25- (T110V), 18- (K232N), and 12- fold (K241F). This improved stability may be due to an altered enzyme- $\mathrm{H}_{2} \mathrm{O}_{2}$ catalysis pathway or to removal of potentially oxidisable residues.
\end{abstract}




\section{Introduction.}

The most widely studied peroxidase is isoform $\mathrm{C}$ from horseradish roots (Armoracia rusticana; HRP) due mainly to its many diverse uses in biotechnology [1]. Peroxidases are prone to suicide inactivation by the $\mathrm{H}_{2} \mathrm{O}_{2}$ substrate, which is particularly problematic in high-value applications such as diagnostics and biosensors [2], as well as in wastewater treatment [3]. The sole report to date of genetic manipulation of HRP in order to improve its peroxide stability used directed evolution, not site-specific mutagenesis as employed here. This study utilised prior art [4] and consensus sequence alignment [5] to select residues for substitution. Most mutants showed little alteration in $\mathrm{H}_{2} \mathrm{O}_{2}$ tolerance compared with wildtype; however, three $(\mathrm{K} 232 \mathrm{~N}, \mathrm{~K} 241 \mathrm{~F}$ and $\mathrm{T} 110 \mathrm{~V})$ exhibit significantly increased $\mathrm{H}_{2} \mathrm{O}_{2}$ tolerance. 


\section{Materials and Methods.}

Materials. The HRP gene was a generous gift from Prof. Frances H. Arnold (Caltech, CA, USA). The pQE60 vector was purchased from Qiagen (Valencia, CA); XL 10 Gold cells and QuickChange ${ }^{\mathrm{TM}}$ Mutagenesis Kit were purchased from Stratagene (La Jolla, CA). All other reagents were purchased from Sigma Aldrich and were of analytical grade or higher.

Cloning. The HRP gene was directionally cloned into the pQE60 vector as a fusion with the N-terminal pectate lyase (PelB) leader sequence [6] and a C-terminal hexahistidine purification tag, to generate the plasmid pBR_I.

Bacterial Strains and Plasmids. E.coli XL 10 Gold was used as host strain. The plasmid (pBR_I), carrying the HRP gene and coding for the HRP fusion protein, was used for expression and site directed mutagenesis.

Recombinant DNA Techniques. All DNA manipulations were carried out by standard techniques [7]. Site directed mutagenesis was carried out as described by Wang and Malcom [8] utilising the QuickChange ${ }^{\mathrm{TM}}$ method. Mutant primers were supplied by MWG-Biotech (Germany). Mutants were confirmed by commercial di-deoxy sequencing (Fusion Antibodies, Belfast, Northern Ireland).

Expression and Purification. XL10 Gold (Stratagene) cells harbouring pBR_I were cultured at $30^{\circ} \mathrm{C}, 220 \mathrm{rpm}$ for $16 \mathrm{~h}$ in $\mathrm{LB}$ broth supplemented with $100 \mu \mathrm{g} / \mathrm{mL}$ ampicillin, $1 \mathrm{mM} \delta$-ALA and $2 \mathrm{mM} \mathrm{CaCl}_{2}$. Post-expression the cells were periplasmically lysed and the contents were precipitated with ammonium sulphate. 
Precipitated protein was resuspended in $50 \mathrm{mM}$ phosphate buffer $\mathrm{pH} 8.0$ and dialysed against same buffer overnight at $4^{\circ} \mathrm{C}$. Sodium chloride (1M) and $\mathrm{GnCl}(200 \mathrm{mM})$ were added to the dialysed fractions, and these latter were subjected to nickel affinity chromatography at room temperature.

$\mathrm{H}_{2} \mathrm{O}_{2}$ Tolerance Analysis: $\mathrm{H}_{2} \mathrm{O}_{2}$ stability of recombinant $\mathrm{HRP}$, and mutant variants, was determined by two methods, as described in references $[9,10]$.

(i) Firstly, rHRP (360 $\mathrm{nM}$ in $50 \mathrm{mM}$ phosphate buffer, $\mathrm{pH} 7.0$ ) was incubated with increasing concentrations of $\mathrm{H}_{2} \mathrm{O}_{2}(0-500 \mathrm{mM}) . \mathrm{H}_{2} \mathrm{O}_{2}$ concentrations were determined spectrophotometrically using $43.6 \mathrm{M}^{-1} \mathrm{~cm}^{-1}$ as the extinction coefficient [11]. Samples were exposed to the relevant $\mathrm{H}_{2} \mathrm{O}_{2}$ concentration for 30 min at $25{ }^{\circ} \mathrm{C}$ in a temperaturecontrolled waterbath. (ii) Secondly, a plot of $\%$ remaining activity versus peroxide/enzyme ratio was generated. Here, the incubation period was increased to 4 hours, the [rHRP] was fixed at $1.6 \times 10^{-5} \mathrm{M}$, and the $\mathrm{H}_{2} \mathrm{O}_{2}$ was varied between 0 and 5 x $10^{-1}$ M. [10] (see Figure 1).

After incubation (either method), $50 \mu \mathrm{L}$ aliquots were withdrawn and remaining catalytic activity was assayed using standard TMB activity assay. This microtitrebased assay comprised $150 \mu \mathrm{L}$ of $32 \mathrm{mM}$ TMB substrate (in $100 \mathrm{mM}$ citric acid buffer, pH 5.5, containing $3 \mathrm{mM} \mathrm{H}_{2} \mathrm{O}_{2}$ ) and $50 \mu \mathrm{L}$ of rHRP in each well. The microplate was shaken as the initiating enzyme was added and the absorbance at 620 $\mathrm{nm}$ was recorded after $6.5 \mathrm{~min}$ reaction time. In each case, the $\mathrm{C}_{50}$ value $\left(\mathrm{mM} \mathrm{H}_{2} \mathrm{O}_{2}\right.$ where $50 \%$ of maximal activity remains, see Table 1) was utilised to compare $\mathrm{H}_{2} \mathrm{O}_{2}$ stabilities across the mutant matrix. 


\section{Results and Discussion.}

Of the twenty-two mutants analysed, three showed highly significant improvements in $\mathrm{C}_{50}$ value for $\mathrm{H}_{2} \mathrm{O}_{2}$ tolerance (see Table 1; T110V, 25-fold; K232N, 18-fold; and K241F, 12fold), four (K232E, K241A, K232/K241N and K232F/K241N) displayed lesser stability gains (between two- and four-fold), whilst the remaining 15 showed decreased or similar-towildtype $\mathrm{H}_{2} \mathrm{O}_{2}$ tolerance. This trend was evident in both 30 min (noted in Table One) and longer 4-hour incubations (Figure One).

In the absence of a reducing substrate, and with excess $\mathrm{H}_{2} \mathrm{O}_{2}$ present, HRP undergoes suicide inactivation. This $\mathrm{H}_{2} \mathrm{O}_{2}$-mediated inactivation has been the subject of much research, with several theories forwarded as to the inactivation pathway. In recent years, however, Hernández-Ruiz and co-workers' [11] “three-pathway model” has gained support. In this model, catalytic competition exists in the presence of excess $\mathrm{H}_{2} \mathrm{O}_{2}$, with three possible outcomes. These are: (a) formation of the dead-end Compound III, (b) a catalase-type reaction, and (c) complete inactivation. The first and second outcomes are enzyme survival routes and selection of one over the other depends on several parameters [11]. If excess $\mathrm{H}_{2} \mathrm{O}_{2}$ persists, the survival pathway is abandoned and the enzyme progressively inactivates, resulting in the formation of inactive verdohaemochrome P670 [12]. The critical point has been identified as the Compound I - peroxide complex. A transient intermediate (P965) has been shown to complex Compound I and the peroxide substrate. Decay of this intermediate, via two competing reactions (survival or inactivation), determines the fate of the enzyme [13].

In this present study, wildtype rHRP yields a $\mathrm{H}_{2} \mathrm{O}_{2} \mathrm{C}_{50}$ of $17 \pm 1 \mathrm{mM}$, which compares with previous published results of $60 \%$ activity in $25 \mathrm{mM} \mathrm{H}_{2} \mathrm{O}_{2}$ [9] under similar conditions. Arnolds and Lin's [9] HRP was expressed in Saccharomyces cerevisiae; perhaps the associated glycosylation aids $\mathrm{H}_{2} \mathrm{O}_{2}$ stability [12]. $\mathrm{K} 232 \mathrm{~N}, \mathrm{~K} 241 \mathrm{~F}$ and $\mathrm{T} 110 \mathrm{~V}$ yielded a 
significant increase in $\mathrm{H}_{2} \mathrm{O}_{2} \mathrm{C}_{50}$ using 30 min incubations. These mutants also exhibited increased thermal and solvent stabilities (up to 2-fold increase in thermal and 3-fold improvement in solvent tolerance; Ryan and Ó'Fágáin, submitted). $\mathrm{H}_{2} \mathrm{O}_{2}$ tolerance of the majority of remaining mutants was equal to, or less than, wildtype.

The T110V mutation notably stabilises HRP against high $\mathrm{H}_{2} \mathrm{O}_{2}$ concentrations. This may be due to the removal of the $-\mathrm{OH}$ moiety of Threonine, which could oxidise to an aldehyde or carboxyl in the presence of the reactive oxygen species generated during $\mathrm{H}_{2} \mathrm{O}_{2}$ catalysis. Valine, although a similarly-sized amino acid, contains only an aliphatic side chain. The importance of space-filling is illustrated by the stabilising K232N, but not K232A, mutation. Additionally, improved $\mathrm{H}_{2} \mathrm{O}_{2}$ tolerance may be achieved by altering the charge of the protein (but maintaining the space-fill characteristics in this region), where the beneficial mutations may have a catalase-type reaction selected over Compound III formation [10]. This could perhaps lead to a HRP-based catalase-type reaction, allowing HRP to maintain catalytic activity in elevated concentrations of $\mathrm{H}_{2} \mathrm{O}_{2}$.

Hiner and co-workers [12] defined the 'partition ratio' as a mechanism for comparing $\mathrm{H}_{2} \mathrm{O}_{2}$ stability of HRP variants over four-hour incubation times at room temperature. This ratio yields the number of $\mathrm{H}_{2} \mathrm{O}_{2}$ turnovers occuring prior to enzyme inactivation. Glycosylation was shown to increase $\mathrm{HRPC} \mathrm{H}_{2} \mathrm{O}_{2}$ stability (2-fold), whilst mutations to the active site (Arg 38 and His 42) caused a 10-fold loss. Partition ratios for the mutants in this study could not be obtained due to the non-linear inactivation data obtained over these longer four hour incubation times (See Figure 1); however, the significant stabilisations due to the mutations are obvious.

As demonstrated by the double lysine substitutions (positions 232 and 241), the beneficial mutations are not additive. Also, a significantly destabilising mutation (Q106R) cannot be "rescued" by inclusion of the stabilising T110V substitution in the combination mutant (see Table One). Mechanistic (NMR, Raman etc.) and structural (crystallisation, saturation 
mutagenesis etc) studies will be required to explain the reason(s) underlying the improved $\mathrm{H}_{2} \mathrm{O}_{2}$ stability of $\mathrm{T} 110 \mathrm{~V}, \mathrm{~K} 232 \mathrm{~N}$ and $\mathrm{K} 241 \mathrm{~F}$. Also, $\mathrm{H}_{2} \mathrm{O}_{2}$ inactivation has been shown by others to effect structural changes, typically affecting the heme moiety, as indicated by an altered Soret band [14]. These points remain to be investigated for the mutants described here.

Previously-reported mutations outside HRP's active site have reduced susceptibility to $\mathrm{H}_{2} \mathrm{O}_{2}$ inactivation: F143A, for example, yields in a $15 \%$ increase in $\mathrm{H}_{2} \mathrm{O}_{2}$ stability [11]. Arnold and Lin [9] improved HRP's $\mathrm{H}_{2} \mathrm{O}_{2}$ stability by directional evolution (65\% increase; L131P and L371I mutations). These mutations also yielded increased thermal and solvent stabilities.

HRP is ranked "intermediate" in $\mathrm{H}_{2} \mathrm{O}_{2}$ protection within the peroxidase superfamily [12]. HRP A2 demonstrates increased $\mathrm{H}_{2} \mathrm{O}_{2}$ tolerance compared with HRPC. This has been attributed to the presence of a modified Compound III in HRP A2-mediated $\mathrm{H}_{2} \mathrm{O}_{2}$ catalysis in the absence of a reducing substrate. Normally, a water molecule is weakly bound to Compound III; however, the altered Compound III replaces this $\mathrm{H}_{2} \mathrm{O}$ molecule with a tightly bound $\mathrm{O}_{2}^{\bullet}$ radical, affording increased stability. The Compound III alternative may be kinetically disfavoured during the HRPC catalytic cycle [12].

Continued mutagenesis studies on other peroxidases highlight the potential for increasing $\mathrm{H}_{2} \mathrm{O}_{2}$ stability [15]. Miyazaki and Takahashi [16] engineered a stabilised $\mathrm{H}_{2} \mathrm{O}_{2}$ binding pocket in a recombinant manganese peroxidase (Class II peroxidase) by Asn81 and multiple Met substitutions. Additionally, a single substitution, H52Q, alters yeast cytochrome $c$ peroxidase (Class I peroxidase) from $\mathrm{H}_{2} \mathrm{O}_{2}$ reduction to oxidation [17]. 


\section{Conclusions.}

Rational and semi-rational (consensus) single-point rHRP substitutions displayed significantly increased $\mathrm{H}_{2} \mathrm{O}_{2}$ stability. T110V exhibited the most dramatic increase in $\mathrm{H}_{2} \mathrm{O}_{2}$ tolerance, and merits further study to elucidate the key interactions causing this stabilisation. A possible pseudo-catalase activity may be inferred from these mutants' ability to function at high concentrations of $\mathrm{H}_{2} \mathrm{O}_{2}$. Double- and multiple-point substitutions were neither synergistic nor additive. $\mathrm{H}_{2} \mathrm{O}_{2}$ tolerant mutants will find many applications in both the highend diagnostic and low-end wastewater treatment markets.

\section{Acknowledgments}

We thank the Irish Research Council for Science, Engineering and Technology (Embark Initiative postgraduate scholarship to BJR) and Dublin City University (Postgraduate Accommodation Award to BJR and Albert College Award to CÓ'F) for financial support. We are also grateful to Prof FH Arnold and California Institute of Technology for the generous gift of a recombinant horseradish peroxidase plasmid. The National Centre for Sensors Research was established under the Higher Education Authority's Programme for Research in Third Level Institutions. 


\section{References.}

1. Ryan B, Carolan N. and O’Fágáin C. (2006). Horseradish and Soybean Peroxidases: Comparable Tools for Alternative Niches? Trends in Biotechnology, 24, 355-363.

2. Borole A, Dai S, Cheng CL, Rodriguez M Jr, Davison BH. (2004). Performance of chloroperoxidase stabilization in mesoporous sol-gel glass using in situ glucose oxidase peroxide generation. Applied Biochemistry and Biotechnology, 113, 273-285

3. Wanger M. and Nicell J.A. (2002). Detoxification of phenolic solutions with horseradish peroxidase and hydrogen peroxide. Water Research, 36, 4041-4052.

4. O’Brien A.M, O’Fágáin C, Nielsen P.F. and Welinder K.G. (2001), Location of Crosslinks in chemically stabilised HRP. Implications for design of crosslinks. Biotechnology and Bioengineering, 76, 277-284.

5. Lehmann M. and Wyss M. (2001). Engineering proteins for thermostability: the use of sequence alignments versus rational design and directed evolution. Current Opinion in Biotechnology, 12, 371-375.

6. Lei S.P, Lin H.C, Wang S.S, Callaway J. and Wilcox G. (1987). Characterisation of the Erwinia carotovora pelB gene and its product pectate lyase. Journal of Bacteriology, 169, 4379-4383

7. Maniatis T, Fritsch E.F. and Sambrook I. (1989) "Molecular Cloning- A laboratory Manual” Cold Spring Harbour Laboratory, Cold Spring Harbour, New York.

8. Wang W. and Malcom B.A. (1999). Two-stage PCR protocol allowing introduction of multiple mutations, deletions and insertions using QuickChange ${ }^{\mathrm{TM}}$ site-directed mutagenesis. BioTechniques, 26, 680-682.

9. Arnold F.H. and Lin, Z. (2000). California Institute Of Technology "Expression of Functional Eukaryotic Proteins". Worldwide Patent: PCT/US99/17127, WO 00/006718.

10. Hiner A.N.P., Hernandez-Ruiz J., Garcia-Canovas F., Smith A.T., Arnao M.B. and Acosta M. (1995). A comparative study of the inactivation of wild-type, recombinant and two mutant horseradish peroxidase isoenzymes C by hydrogen peroxide and m-chloroperoxybenzoic acid. European Journal of Biochemistry, 234, 506-512. 
11. Hernández-Ruiz J, Arnao M.B, Hiner A.N.P, Garcia-Cánovas F. and Acosta M. (2001). Catalase-like activity of horseradish peroxidase: relationship to enzyme inactivation by $\mathrm{H}_{2} \mathrm{O}_{2}$. Biochemical Journal, 354, 107-114.

12. Hiner A.N, Hernández-Ruiz J, Rodríguez-López J, Arnao M.B, Varón R, García-Cánovas F and Acosta M. (2001). The inactivation of horseradish peroxidase isoenzyme A2 by hydrogen peroxide: an example of partial resistance due to the formation of a stable enzyme intermediate. Journal of Biological Inorganic Chemistry, $\mathbf{6}$, 504-516.

13. Hiner A.N.P, Raven E.L, Thorneley R.N.F, Garcia-Canovas F. and Rodriguez-Lopez J.N. (2002). Mechanisms of Compound I formation in heme peroxidases. Journal of Inorganic Biochemistry, 91, 27-34

14. Schmidt A, Schumacher J.T, Reichelt J, Hecht H-J. and Bilitewski U. (2002). Mechanistic and molecular investigation on stabilisation of HRPC. Analytical Chemistry 74, 3037-3045.

15. Valderrama B, Ayala M. and Vazquez-Duhalt R. (2002). Suicide inactivation of peroxidases and the challenge of engineering more robust enzymes. Chemistry and Biology, 9, 555-565.

16. Miyazaki C. and Takahashi H. (2001). Engineering of the $\mathrm{H}_{2} \mathrm{O}_{2}$-binding pocket region of a recombinant manganese peroxidase to be resistant to $\mathrm{H}_{2} \mathrm{O}_{2}$. FEBS Letters, 509, 111-114.

17. Bateman L, Leger C, Goodin D.B. and Armstrong F.A. (2001). A distal histidine mutant (H52Q) of Yeast Cytochrome $c$ Peroxidase catalyses the oxidation of $\mathrm{H}_{2} \mathrm{O}_{2}$ instead of its reduction. Journal of the American Chemical Society, 123, 9260-9263. 


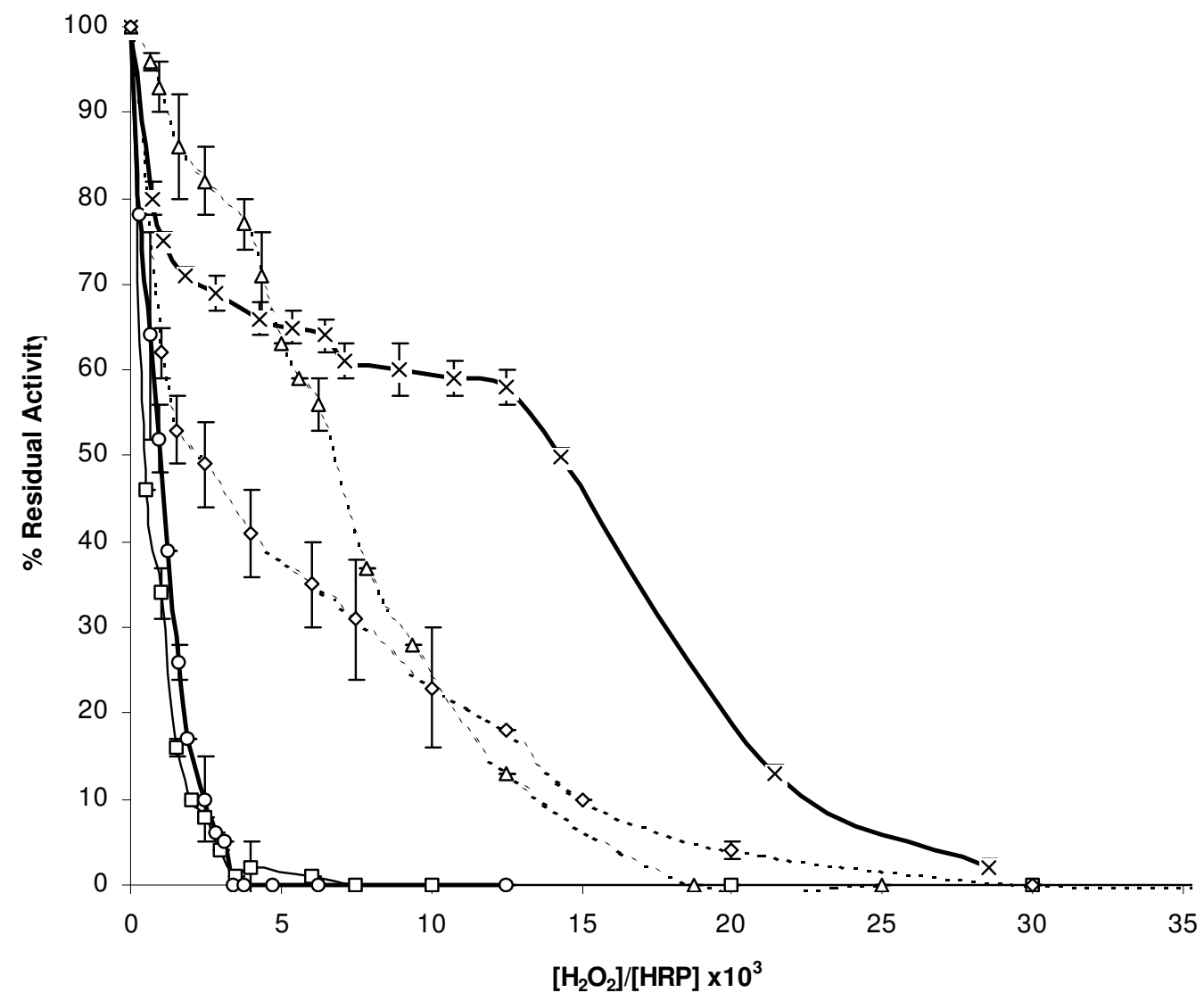

Figure 1: Plot of \% remaining activity versus peroxide/enzyme ratio for plant HRP, wildtype rHRP and stabilised rHRP mutants over $4 \mathrm{~h}$ at room temperature. $\square$ Plant HRP, $\circ \mathrm{rHRP}, \diamond \mathrm{K} 241 \mathrm{~F}, \Delta \mathrm{K} 232 \mathrm{~N}, \mathrm{x}$ T110V. 
Table I: $\mathrm{C}_{50}$ values for $\mathrm{H}_{2} \mathrm{O}_{2}$ (the $\mathrm{mM} \mathrm{H}_{2} \mathrm{O}_{2}$ concentration that reduces catalytic activity to half the initial value in aqueous solution) for a selection of the mutants investigated (30 min incubation at room temperature). Single letter amino acid nomenclature is used throughout: A, Alanine; E, Glutamic Acid; F, Phenylalanine; K, Lysine; N, Asparagine. Combination mutant is T102A/Q106R/Q107D/T110V/I180F. The number indicates the relative position in the HRP structure (1ATJ, PDB accession code).

\begin{tabular}{c|c|c|c}
$\begin{array}{c}\text { Mutant } \\
\text { Name }\end{array}$ & $\begin{array}{c}\mathbf{H}_{2} \mathbf{O}_{2} \mathbf{C}_{\mathbf{5 0}} \\
(\mathbf{m M})\end{array}$ & $\begin{array}{c}\text { Error } \\
(\%)\end{array}$ & $\begin{array}{c}\text { Fold } \\
\text { Improvement }\end{array}$ \\
\hline Wildtype & $\mathbf{1 7}$ & $\pm \mathbf{4}$ & -- \\
Q106R & 7 & \pm 6 & -- \\
T110V & 425 & \pm 11 & 25 \\
K232N & 300 & \pm 5 & 18 \\
K232E & 36 & \pm 10 & 2 \\
K232A & 19 & \pm 6 & -- \\
K241A & 33 & \pm 6 & 2 \\
K241F & 200 & \pm 7 & 12 \\
K232/241N & 65 & \pm 5 & 4 \\
K232F/K241N & 70 & \pm 8 & 4 \\
Combination & 8 & \pm 1 & --
\end{tabular}




\section{Supplementary Online Material.}

Methods.

Cloning.

Initially, the PelB leader was cloned via a Nco I - BamH I double restriction. This introduced a novel Not I site 5' to the existing BamH I site in the modified pQE60 vector. The HRP gene was then Not I - Bgl II directionally cloned into a Not I BamH I restricted PelB-modified pQE60 vector. This cloning strategy incorporated the poly-His tag, present in the pQE60 vector, at the C-terminus of HRP.

Expression and Purification.

A single cell transformed with pBR_I (or mutant derivative) was grown in LB medium containing $100 \mu \mathrm{g} / \mathrm{mL}$ ampicillin and $2 \% \mathrm{w} / \mathrm{v}$ glucose until the $\mathrm{OD}_{600 \mathrm{~nm}}$ reached 0.4 ; the cells were removed via centrifugation at $2,000 \times g$ for 5 min and resuspended in fresh LB supplemented with $100 \mu \mathrm{g} / \mathrm{mL}$ ampicillin, $1 \mathrm{mM} \delta$-ALA and $2 \mathrm{mM} \mathrm{CaCl}{ }_{2}$. The cells were then allowed to grow at $30^{\circ} \mathrm{C}, 220 \mathrm{rpm}$ for $16 \mathrm{~h}$. Following overnight expression, the cells were centrifuged as before and the supernatant was treated with $50 \% \mathrm{w} / \mathrm{v}$ ammonium sulphate (with respect to the initial supernatant volume) for $2 \mathrm{~h}$ at room temperature. The cells were periplasmically lysed and the periplasmic contents were similarly treated with $50 \%$ w/v ammonium sulphate. Proteins precipitated by ammonium sulphate were collected via centrifugation as before, resuspended in $50 \mathrm{mM}$ phosphate buffer $\mathrm{pH} 8.0$ and dialysed versus the same buffer overnight at $4^{\circ} \mathrm{C}$. Sodium chloride (1M) and $\mathrm{GnCl}(200 \mathrm{mM})$ were added to the dialysed fractions, and these latter were subjected to nickel affinity chromatography at room temperature. Sodium acetate $(25 \mathrm{mM}, \mathrm{pH} 4.5)$ was utilised to elute the bound HRP. The eluted HRP was again dialysed versus $50 \mathrm{mM}$ phosphate buffer $\mathrm{pH} 7.5$ overnight at $4^{\circ} \mathrm{C}$, after which the protein was concentrated (AmiconPlus 20 concentrator tubes), filter sterilised and stored at $4^{\circ} \mathrm{C}$. 